\title{
B-Z Conformational Transition of DNA Monitored by Vibrational Circular Dichroism. Ab Initio Interpretation of the Experiment
}

\author{
Valery Andrushchenko, ${ }^{\dagger}$ Helmut Wieser, ${ }^{\dagger}$ and Petr Bouřr*, \\ Department of Chemistry, University of Calgary, 2500 University Dr., Calgary AB, T2N 1N4, Canada and \\ Institute of Organic Chemistry and Biochemistry, Academy of Sciences of the Czech Republic, \\ Flemingovo nám. 2, 16610, Praha 6, Czech Republic
}

Received: June 10, 2002; In Final Form: September 13, 2002

\begin{abstract}
The $\mathrm{B}-\mathrm{Z}$ conformational transition was induced by $\mathrm{Mn}^{2+}$ ions in a synthetic oligonucleotide $(\mathrm{dG}-\mathrm{dC})_{20}$ and monitored by the vibrational circular dichroism (VCD). For the first time, the spectra were analyzed on the basis of quantum-mechanical computations. Force field and intensity tensors computed ab initio for smaller DNA fragments were transferred to a d(GCGCGCGC) $)_{2}$ octamer model including explicit water molecules. The method allowed us to assign and explain most of the frequency and intensity features observed in the absorption and VCD spectra of the B- and Z-forms. Particularly, the computations reproduced the VCD sign flip caused by the transition due to the $\mathrm{C}=\mathrm{O}$ stretching and allowed us to assign most spectral bands in the nitrogen bases vibrational region. Also, known isotopic effects (deuteration and a ${ }^{18} \mathrm{O}$ substitution) were reproduced correctly. For the sugar-phosphate modes, the assignment of the VCD bands was hindered by a weak experimental signal. The approach based on quantum-mechanical computations was found superior to previous models based on coupled oscillator theory. Water molecules hydrogen-bonded to the DNA skeleton had to be included for reliable interpretation of the VCD and IR spectral patterns, namely, for the sugarphosphate vibrations.
\end{abstract}

\section{Introduction}

The $\mathrm{B}-\mathrm{Z}$ conformational transition is a well-documented phenomenon, first observed for the synthetic polynucleotide poly $(\mathrm{dG}-\mathrm{dC}) \cdot \operatorname{poly}(\mathrm{dG}-\mathrm{dC})$ in $1972 .{ }^{1}$ The natural B-form, that is a right-handed helix, transforms to the left-handed $\mathrm{Z}$ conformation when high amounts of salts $^{1}$ or ethanol ${ }^{2}$ are added to water solutions. Several monovalent, divalent, and multivalent ions, including $\mathrm{Mn}^{2+}$, can induce the $\mathrm{B}-\mathrm{Z}$ transition of poly$(\mathrm{dG}-\mathrm{dC}) \cdot \operatorname{poly}(\mathrm{dG}-\mathrm{dC}){ }^{3,4}$ While in right-handed duplexes (Bconformation), the phosphate groups in the polynucleotide chains are located at the same helical radius and are equivalent; in the left-handed helix $(\mathrm{Z})$, the phosphates in the $\mathrm{d}(\mathrm{CpG})$ sequence (where " $p$ " stands for a phosphate linkage between $C$ and $\mathrm{G})$ are closer to the helical axes than in the $\mathrm{d}(\mathrm{GpC})$ sequence and their conformations differ. ${ }^{5}$ These two different phosphate orientations have been designated as $\mathrm{Z}_{\mathrm{I}}$ and $\mathrm{Z}_{\mathrm{II}} \cdot{ }^{6}$ Later, the lefthanded sequences have been found in natural DNA and are believed to play a significant role in several important life processes, such as gene regulation and DNA replication. ${ }^{7}$ Recently, a protein specifically recognizing the Z-form of DNA has been isolated in vitro from several mammalian tissues. ${ }^{8,9}$

The $\mathrm{B}-\mathrm{Z}$ transition was first monitored by the electronic circular dichroism (ECD). ${ }^{1}$ The most prominent evidence of the transition is an inversion of the ECD spectra. However, because of a limited number of measurable UV transitions, which correspond to relatively delocalized excitations of the molecules often resulting in broad and overlapping ECD spectral bands, it is difficult to obtain information about specific functional groups and local molecular structure. ${ }^{10}$ Lately, the vibrational

* To whom the correspondence should be addressed. E-mail: bour@ uochb.cas.cz. Fax: (420-2)-2431-0503.

† University of Calgary. E-mail: vandrush@ucalgary.ca, hwieser@ ucalgary.ca.

$\doteqdot$ Academy of Sciences of the Czech Republic. circular dichroism (VCD) technique has been used for DNA conformational studies including $\mathrm{B}-\mathrm{Z}$ transitions. ${ }^{11-13} \mathrm{VCD}$ exhibited several advantages over ECD, namely, a more local character of the optically active vibrational transitions. ${ }^{10}$ Moreover, it was shown that the VCD spectral patterns invert during the $\mathrm{B}-\mathrm{Z}$ transition, in both the nitrogen bases $(\sim 1500-1700$ $\left.\mathrm{cm}^{-1}\right)$ and sugar-phosphate $\left(\sim 800-1100 \mathrm{~cm}^{-1}\right)$ frequency regions, that is, they reflect the change of the helical twist from the right- to the left-handed helix similarly as the ECD spectra. ${ }^{11-13}$

In nucleic acids, the VCD signal arises mainly from throughspace dipolar coupling among characteristic chromophoresnucleobases and the sugar-phosphate backbone residues. ${ }^{10,11,14}$ Typically, such an interaction is observed as a couplet-VCD feature with close positive and negative components of approximately same size-called either positive or negative when the component at lower wavenumber is either positive or negative, respectively. The coupling is very sensitive to the distances and mutual orientations of the chromophores, which is reflected in the high sensitivity of the spectra to the changes in molecular structure.

Despite the extensive information about the origin of IR absorption bands gathered to date, some of the assignments are not clear or are ambiguous. ${ }^{6,15,16}$ Even less information is available about the assignments of the VCD couplets and bands, which significantly diminishes the structural information that can be extracted from the spectra. Thus, the principal aim of our work is to provide more complete assignments of absorption and particularly VCD DNA bands, as well as to develop computational methods suitable for systems of similar complexity.

In practice, VCD spectra can be also interpreted more easily than ECD because most molecular vibrational transitions occur only in electronic ground states. ${ }^{17}$ However, the size of 


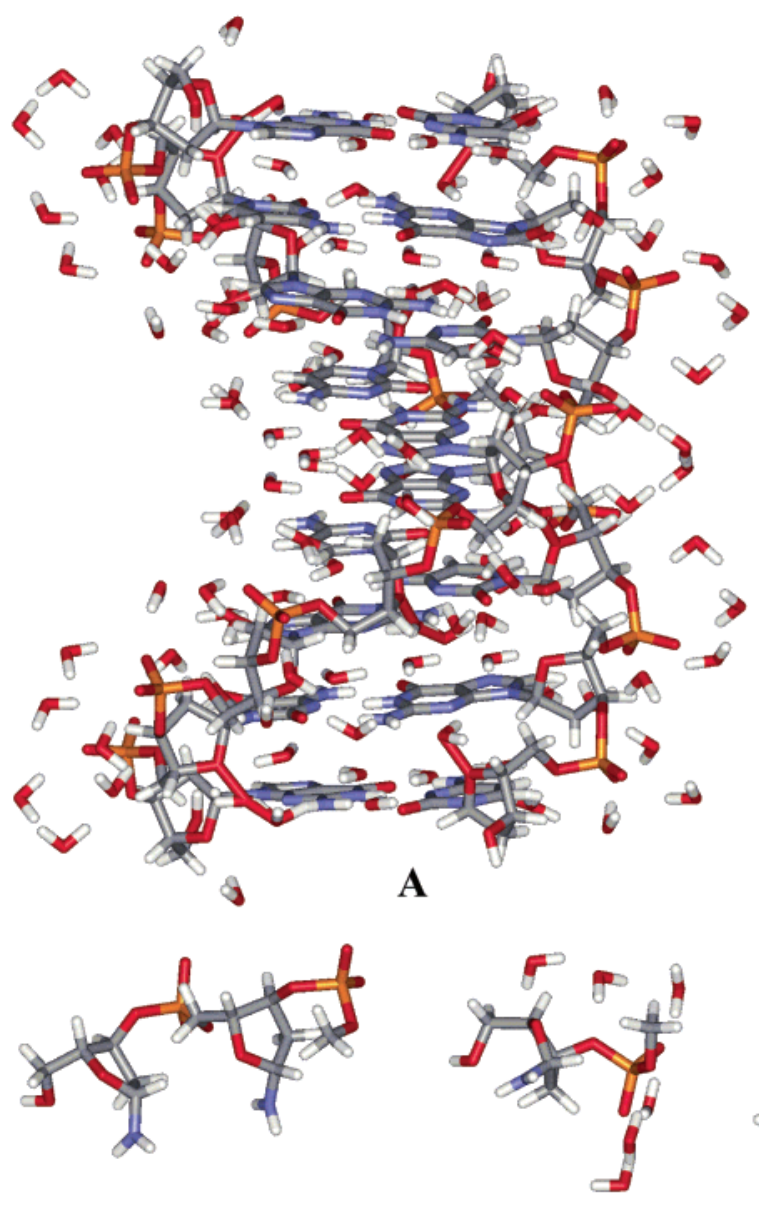

D

$\mathbf{E}$
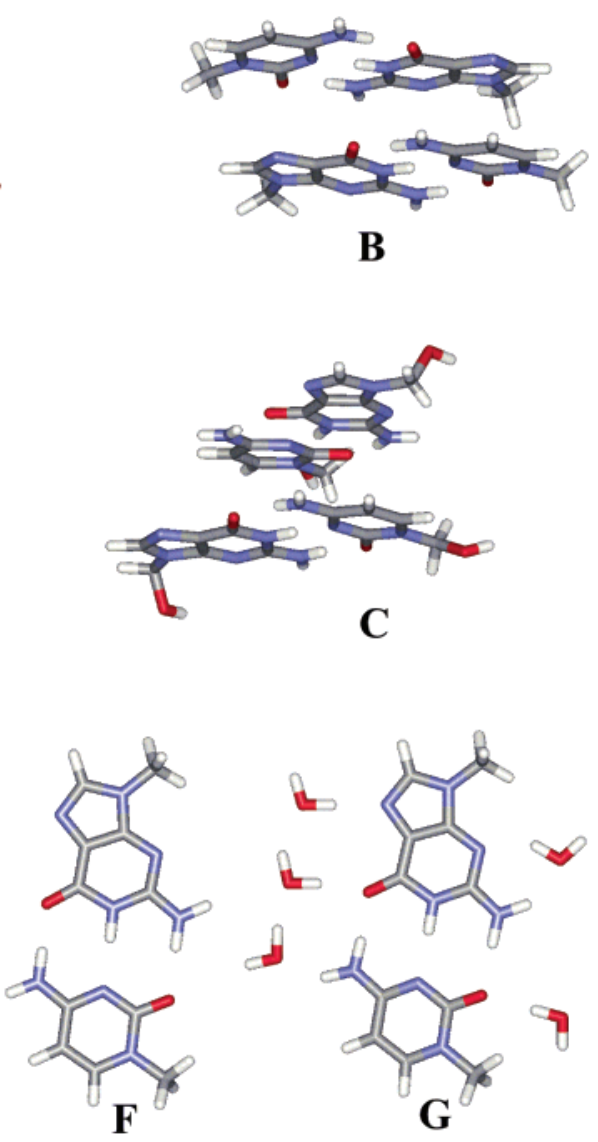

Figure 1. The target $\mathrm{d}(\mathrm{GCGCGCGC})_{2} \cdot 124 \mathrm{H}_{2} \mathrm{O}$ system (A) for B-conformation and the fragments used as sources of the force field: $(\mathrm{C} \text {...G })_{2}(\mathrm{~B})$ and $(\mathrm{G} . . . \mathrm{C})_{2}(\mathrm{C})$ "dinucleotides", a sugar-phosphate dimer (D), hydrated sugar-phosphate monomer (E), the G...C base pair (F), and a hydrated $\mathrm{G} . . . \mathrm{C} \cdot 5 \mathrm{H}_{2} \mathrm{O}$ base pair $(\mathrm{G})$. Analogous fragmentation was used for the $\mathrm{Z}$-conformation.

macromolecules still prevents a direct quantum-mechanical modeling of a sufficient accuracy. In the past, semiempirical models such as the coupled oscillator $(\mathrm{CO})$ were used for the VCD simulations. ${ }^{11,12,18-21}$ The CO model provided a good basis for understanding the main intensity features observed in the $\mathrm{C}=\mathrm{O}$ stretching region but failed for many other cases. Particularly, it was shown that the model should not be applied when the chromophores are close in space, which is the case for stacked DNA bases. ${ }^{22,23}$ Models describing the harmonic vibrations using generalized molecular-mechanics force fields are not accurate enough for the fine-band splitting needed for VCD spectra, nor do they provide spectral intensities. Thus, the ab initio approach appears most viable for the spectral modeling. Despite necessary simplifications that must be adopted for particular systems, the methodology is opened to systematic improvement.

In the past, ab initio computations on smaller molecular fragments were successfully used for reproduction of VCD spectra of standard peptide conformations. ${ }^{24-26}$ Local interactions between neighboring amide groups contributed the most to peptide and protein VCD spectra, and most of the spectral features could be explained already with a dipeptide molecule at a rather low HF/4-31G level of approximation. ${ }^{24}$ Significant increase of precision in calculated harmonic vibrational frequencies for peptides was achieved later by using modern DFT functionals requiring only a small increase of computer power if compared to HF. ${ }^{26}$ The magnetic field perturbation theory (MFP) of Stephens implemented with field-dependent atomic orbitals has been proven to provide reliable estimates of VCD intensities. ${ }^{27}$ The ab initio computations on smaller systems could be extended to bigger molecules more reliably when the atomic tensors (force field, dipole derivatives, atomic axial tensor) were transferred from smaller systems. ${ }^{28}$

In the present study, we construct spectroscopic properties of a model octanucleotide on the basis of ab initio computations of smaller DNA fragments. As shown below, such an approach enables a detailed insight into the dependence of DNA vibrational properties on molecular structure and conformation.

\section{Method}

2.1. Experiment. A desalted self-complimentary oligonucleotide (dG-dC) $)_{20}$ (40 base pairs in total) was obtained from the University of Calgary Core DNA Services. $\mathrm{MnCl}_{2}$ salt was purchased from Sigma Chemicals. The oligonucleotide was dissolved in cacodylic buffer containing $0.02 \mathrm{M}$ sodium cacodylate and $0.06 \mathrm{M} \mathrm{NaCl}$ at $\mathrm{pH}=6.8$. The $\mathrm{MnCl}_{2}$ solution was prepared with the same buffer. All spectra measurements were done with $\mathrm{D}_{2} \mathrm{O}$ as a solvent. The complete deuterium exchange was achieved by lyophilizing and redissolving all solutions three times in $\mathrm{D}_{2} \mathrm{O}$. After the lyophilization, the $\mathrm{Mn}^{2+}$ concentration was determined by a titration using the pyridylazoresorcinol indicator, and the oligonucleotide concentration was determined by a UV absorption at $260 \mathrm{~nm}$.

The oligonucleotide sample was contained in a demountable cell (International Crystal Laboratories, Inc.) composed of two 
<smiles>Cn1ccc(N)nc1=O</smiles>

Me-C

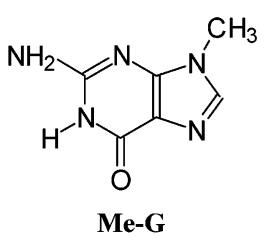

Figure 2. $N$-methyl-cytosine (Me-C) and $N$-methyl-guanine (Me-G), vibrational spectra of which were used for classification of the modes in Table 1 .

$\mathrm{BaF}_{2}$ windows separated by a $50 \mu \mathrm{m}$ Teflon spacer. The concentration of the oligonucleotide in the spectroscopic cell was $26 \mathrm{mg} / \mathrm{mL}(\sim 0.085 \mathrm{M}$ of oligonucleotide phosphates or $\sim 0.0011 \mathrm{M}$ of the oligonucleotide duplex). The $\mathrm{Mn}^{2+}$ concentration in the spectroscopic cell was $0.74 \mathrm{M}$ (or $8.5[\mathrm{Mn}] /[\mathrm{P}]$, where $[\mathrm{Mn}] /[\mathrm{P}]$ represents the number of moles of the $\mathrm{Mn}^{2+}$

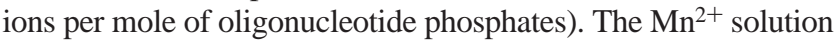
was added dropwise to the oligonucleotide solution continuously stirred on one cell window.

All VCD and absorption spectra were measured in the range of $1800-800 \mathrm{~cm}^{-1}$ with a VCD instrument described elsewhere. ${ }^{29}$ The temperature of the sample was $25^{\circ} \mathrm{C}$. A total of 7500 AC scans was accumulated for the VCD spectra $(2 \mathrm{~h} 45$ min) and rated against 750 DC scans for the absorption spectra, all at a resolution of $4 \mathrm{~cm}^{-1}$. The VCD spectra were corrected for polarization artifacts by subtracting spectra of the solvent obtained under the same conditions.

2.2. Calculations. Because of the extreme demands of current ab initio methods on computer time and memory, ${ }^{30}$ molecular property tensors of the large target molecules were constructed from their smaller fragments using a transfer technique described previously. ${ }^{26,28}$ The transfer is based on translations and rotations of the tensors calculated precisely in Cartesian coordinates for the smaller systems. For VCD, force constants (second-energy derivatives, $f_{i \alpha, j \beta}=\partial^{2} E / \partial r_{i \alpha} \partial r_{j \beta}$ ), atomic polar (dipole derivatives, $P_{\alpha, i \beta}=\partial \mu_{\alpha} / \partial r_{i \beta}$ ), and axial (magnetic dipole derivatives, $A_{\alpha, i \beta}$ $=\partial m_{\alpha} / \partial p_{i \beta}$ ) tensors have to be calculated to obtain the frequencies and intensities. ${ }^{17}$ The force constants are thus related to two atoms $(i, j)$ while the tensors $\mathbf{A}$ and $\mathbf{P}$ can be though of as properties of individual atoms $i$ of positions $\boldsymbol{r}_{i}$ and momenta $\boldsymbol{p}_{i}$. This enables to define the transfer-rotation and translationby a root-mean square overlap of chemically similar atoms in the smaller and target molecule. ${ }^{28}$ A program written in house ("cct.f") was used for the tensor manipulations. As follows from our previous experience, if the fragments are chosen carefully, the method provides IR and VCD spectra virtually indistinguishable from fully ab initio results. ${ }^{31}$ Particularly, the method was suitable for spectroscopic studies of the peptide secondary structure. . $^{25,26}$

A double-stranded octanucleotide 5'd(GCGCGCGC)3' (all oligonucleotide sequences hereafter are indicated in $5^{\prime}-3^{\prime}$ direction) was used as a target molecule, referred to as $\mathrm{d}(\mathrm{GCGCGCGC})_{2}$. According to the experimental experience, the IR absorption and VCD spectra of d(GCGCGCGC) 2 are essentially identical to those of longer polymers, e.g., $(\mathrm{dG}-\mathrm{dC})_{20} \cdot{ }^{13,14,30,32}$ This allowed us to use a computationally more convenient shorter sequence with eight base pairs for the modeling and compare its spectra directly to the experimental data for the longer molecules (with 40 base pairs). The geometry of the octamer in the standard B- and Z-conformations was generated using the Biosym software ${ }^{33}$ with parameters based on X-ray and NMR data. The target octamer with explicit water molecules (structure A in Figure 1) was divided into several repeating fragments used for ab initio computations; a terminal distortion of the Biosym idealized structure was not considered. The fragments included two GC base pairs stacked on top of each other (designated as $(\mathrm{G} . . \mathrm{C})_{2}$ and $(\mathrm{C} . . \mathrm{G})_{2}$ corresponding to the $5^{\prime} \mathrm{d}(\mathrm{GC}) 3^{\prime}$ and $5^{\prime} \mathrm{d}(\mathrm{CG}) 3^{\prime}$ dinucleotides, from which they were obtained by cutting out the sugar-phosphate linkages, see $\mathrm{B}$ and $\mathrm{C}$ in Figure 1), a sugar-phosphate dimer (designated hereafter as SPSP, D in Figure 1), a sugar-phosphate monomer with six explicit water molecules (SP-6W, E), and a single CG base pair without $(\mathrm{F})$ and with $(\mathrm{G})$ water molecules. Positions of the water molecules were partially optimized so that the oxygen, nitrogen, and the acidic hydrogen atoms in DNA exposed to the solvent could form hydrogen bonds. The positions were in agreement with the previous ab initio calculations of explicit water molecules around the nucleic acid base pairs. ${ }^{34}$ The $N$-methylcytosine and $N$-methylguanine (Me-C and $\mathrm{Me}-\mathrm{G}$, see Figure 2) molecules were not included in the simulation, but their vibrations were used for classification of the normal modes. Attempts to include larger fragments in the computations, e.g., full-double-stranded dinucleotides $5^{\prime} \mathrm{d}(\mathrm{GC})$ -

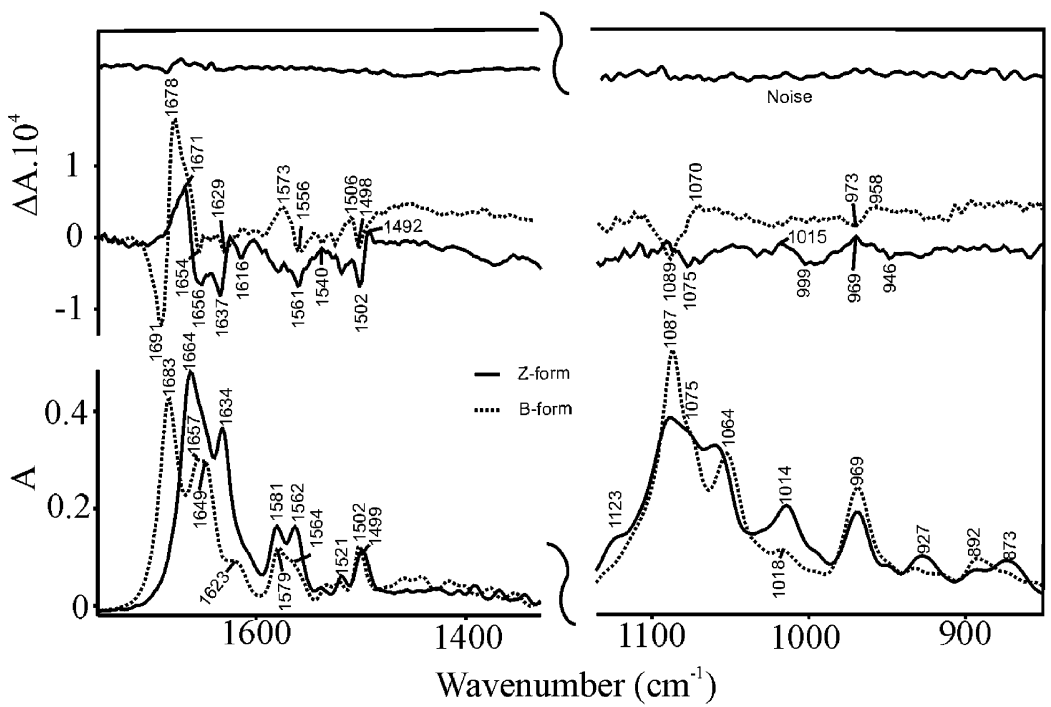

Figure 3. Experimental absorption $(\mathrm{A})$ and $\operatorname{VCD}(\Delta \mathrm{A})$ spectra of the $\mathrm{B}$ - and Z-conformations of (dG-dC $)_{20}$. At the top, the noise estimate is given for the VCD signal, obtained by subtracting two consecutively recorded spectra of the same sample and divided by two. The B-form was measured without, the Z-form with metal ions $\left(0.74 \mathrm{M} \mathrm{Mn}^{2+}\right)$, both in $\mathrm{D}_{2} \mathrm{O}$ solution. 
TABLE 1: Building Blocks of Nucleic Acid and Their Characteristic Frequencies $\left(\mathrm{cm}^{-1}\right)$; All Calculations Are Presented for Deuterated Molecules

(a) Single Bases

\begin{tabular}{|c|c|c|c|c|}
\hline $\begin{array}{l}\text { BPW91 } \\
6-31 G \\
\end{array}$ & $\begin{array}{l}\text { BPW91 } \\
6-31 G^{* *} \\
\end{array}$ & $\begin{array}{c}\text { BPW91 } \\
6-311++\mathrm{G}^{* *}\end{array}$ & $\begin{array}{c}\text { dominant } \\
\text { displacement }\end{array}$ & $\begin{array}{l}\text { experimental bands for } \\
\text { nonmethylated bases }{ }^{a}\end{array}$ \\
\hline \multicolumn{5}{|c|}{ Me-Cytosine } \\
\hline 1675 & 1743 & 1703 & $v^{c}(\mathrm{C}=\mathrm{O})$ & 1652 \\
\hline 1639 & 1653 & 1634 & $v(\mathrm{C}=\mathrm{C})$ ring & 1616 \\
\hline 1526 & 1526 & 1512 & $v(\mathrm{C}=\mathrm{C})$ ring & 1525 \\
\hline 1483 & 1507 & 1487 & $v(\mathrm{C}=\mathrm{N})$ ring & 1503 \\
\hline \multicolumn{5}{|c|}{ Me-Guanine } \\
\hline 1709 & 1770 & 1733 & $v(\mathrm{C}=\mathrm{O})$ & 1665 \\
\hline 1573 & 1581 & 1561 & $v(\mathrm{C}=\mathrm{N})$ ring & 1581,1568 \\
\hline 1551 & 1555 & 1542 & $\nu(\mathrm{C}=\mathrm{N}, \mathrm{C}=\mathrm{C}) \operatorname{ring}$ & 1539 \\
\hline 1507 & 1529 & 1516 & $\nu(\mathrm{C}=\mathrm{N}, \mathrm{C}=\mathrm{C})$ ring & \\
\hline 1461 & 1479 & 1464 & $v(\mathrm{CNH} 2)$ & \\
\hline 1430 & 1418 & 1458 & $\mathrm{~d}(\mathrm{C}-\mathrm{H}), v(\mathrm{C}=\mathrm{N})$ ring & \\
\hline
\end{tabular}

(b) The G...C Base Pair

\begin{tabular}{|c|c|c|c|c|c|c|}
\hline $\begin{array}{l}\text { BPW91 } \\
6-31 \mathrm{G}\end{array}$ & $\begin{array}{l}\text { BPW91 } \\
6-31 G^{* *}\end{array}$ & $\begin{array}{c}\text { BPW91 } \\
6-31 \mathrm{G}^{* *}+5 \mathrm{H} 2 \mathrm{O}\end{array}$ & $\begin{array}{c}\text { BPW91 } \\
6-311++\mathrm{G}^{* *}\end{array}$ & $\begin{array}{c}\text { dominant } \\
\text { displacement }\end{array}$ & $\begin{array}{l}\text { experimental } \\
\text { bands }^{a}\end{array}$ & $\begin{array}{l}\text { mode numbers } \\
\text { in Figure } 4\end{array}$ \\
\hline 1667 & 1698 & 1695 & 1671 & $v(\mathrm{C}=\mathrm{O}) / \mathrm{G}+v(\mathrm{C}=\mathrm{O}) / \mathrm{C}$ & 1688 & 1 \\
\hline 1643 & 1651 & 1652 & 1632 & $v(\mathrm{C}=\mathrm{C}) /$ ring $\mathrm{C}$ & & 2 \\
\hline 1625 & 1676 & 1666 & 1645 & $v(\mathrm{C}=\mathrm{O}) / \mathrm{C}$ & 1647 & 3 \\
\hline 1575 & 1580 & 1598 & 1558 & $v\left(\mathrm{CNH}_{2}\right) / \mathrm{G}$ & 1585,1581 & 4 \\
\hline 1557 & 1564 & 1574 & 1548 & $\nu(\mathrm{C}=\mathrm{N}) /$ ring $\mathrm{G}$ & 1568 & 5 \\
\hline 1538 & 1544 & 1559 & 1520 & $v\left(\mathrm{CNH}_{2}\right) / \mathrm{C}$ & 1539,1525 & 6 \\
\hline 1504 & 1505 & 1502 & 1487 & $v(\mathrm{C}=\mathrm{N}, \mathrm{C}=\mathrm{C}) \operatorname{ring} \mathrm{C}$ & 1503 & \\
\hline 1495 & 1527 & 1534 & 1514 & $v(\mathrm{C}=\mathrm{N}, \mathrm{C}=\mathrm{C}) \operatorname{ring} \mathrm{G}$ & & 7 \\
\hline 1477 & 1477 & 1477 & 1467 & $v(\mathrm{C}=\mathrm{N}) \operatorname{ring} \mathrm{G}$ & & 8 \\
\hline
\end{tabular}

(c) $(\mathrm{C} \ldots \mathrm{G})_{2}$ fragment

\begin{tabular}{|c|c|c|c|}
\hline $\begin{array}{c}\text { BPW91 } \\
\text { 6-31G (Z-form) }\end{array}$ & $\begin{array}{c}\text { BPW91 } \\
\text { 6-31G**(Z-form) }\end{array}$ & $\begin{array}{c}\text { BPW91 } \\
6-31 \mathrm{G}^{* *} \text { (B-form) }\end{array}$ & dominant displacement \\
\hline 1667,1658 & 1697,1685 & 1712,1691 & $v(\mathrm{C}=\mathrm{O}) / \mathrm{G}$ \\
\hline 1640,1634 & 1642,1639 & 1655,1654 & $v(\mathrm{C}=\mathrm{C}) / \mathrm{C}+\mathrm{C}=\mathrm{O} / \mathrm{G}$ \\
\hline 1616,1604 & 1669,1656 & 1671,1682 & $v(\mathrm{C}=\mathrm{O}) / \mathrm{C}$ \\
\hline 1566,1563 & 1576,1576 & 1602,1584 & $v\left(\mathrm{CNH}_{2}\right) / \mathrm{G}$ \\
\hline 1555,1550 & 1562,1560 & 1574,1565 & $v(\mathrm{C}=\mathrm{N}) / \mathrm{G}$ \\
\hline 1525,1522 & 1536,1533 & 1540,1536 & $\delta\left(\mathrm{CNH}_{2}\right)+$ de $\mathrm{f} / \mathrm{C}$ \\
\hline
\end{tabular}

(d) $(\mathrm{G} \text {...C })_{2}$ Fragment

\begin{tabular}{cccc}
\hline BPW91 & BPW91 & BPW91 \\
6-31G (Z-form) & 6-31G**(Z-form) & $\begin{array}{c}\text { dominant displacement } \\
\text { 6-31G**(B-form) }\end{array}$ & $v(\mathrm{C}=\mathrm{O}) / \mathrm{C}$ \\
1694,1631 & 1676,1663 & 1682,1664 & $v(\mathrm{C}=\mathrm{O}) / \mathrm{G}$ \\
1675,1667 & 1703,1694 & 1703,1697 & $v(\mathrm{C}=\mathrm{C}) / \mathrm{C}+\mathrm{C}=\mathrm{O} / \mathrm{G}$ \\
1661,1647 & 1645,1644 & 1654,1652 & $v(\mathrm{CNH}) / \mathrm{G}$ \\
1587,1573 & 1576,1571 & 1583,1572 & $\mathrm{~N}) / \mathrm{G}$ \\
1555,1554 & 1558,1557 & 1561,1560 & $v(\mathrm{CNH})+\mathrm{de} \mathrm{f} / \mathrm{C}$
\end{tabular}

(e) Sugar-Phosphate Dimer

\begin{tabular}{clc}
\hline BPW91/6-31 G** & \multicolumn{1}{c}{ assignment } & experimental bands $^{b}$ \\
\hline $1460-1447$ & $\mathrm{CH}_{2}$ scissoring vibrations & \\
$1402-1184$ & $\delta(\mathrm{C}-\mathrm{H})$ & 1225 \\
1242 & asymmetric $v(\mathrm{P}=\mathrm{O})$ coupled with $\delta(\mathrm{CH})$ & 1084 \\
$1161-1040$ & $v(\mathrm{CC})$ and skeletal deformations & 1050,1015 \\
1080 & symmetric $v(\mathrm{P}=\mathrm{O})$ coupled with $\mathrm{C}^{\prime}-\mathrm{O}^{\prime}$ & \\
1022 & $v(\mathrm{C}-\mathrm{O})$ of the deoxyribose ring & $967,890,830$ \\
$<1022$ & phosphodiester backbone coupled to sugar motions and glycosidic bond torsion & \\
${ }^{a}$ References 15 and $16 .{ }^{b}$ References 6,15, and $16 .{ }^{c} v$, stretching; $\delta$, bending.
\end{tabular}

$3^{\prime}$ and $5^{\prime} \mathrm{d}(\mathrm{CG}) 3^{\prime}$, failed because of the excessive demands on computer time.

The geometries of the target octanucleotides were not changed during the calculation. However, the smaller fragments were partially optimized with torsion angles constrained to those in the octamer to relax the stretching and bending modes visible in the experimental spectra. In the two stacked base pairs $(\mathrm{G} . . . \mathrm{C})_{2}$ and $(\mathrm{C} . . . \mathrm{G})_{2}$, the distances and mutual orientations of the base pairs were also constrained to maintain their realistic values in the absence of the sugar-phosphate support.

For the fragments, the relaxed geometries, harmonic force fields, dipole derivatives, and the atomic axial tensors were calculated with the Gaussian 98 suite of programs. ${ }^{35}$ The DFT BPW $91^{36,37} / 6-31 \mathrm{G}^{* *}$ level was used as a primary approximation, since it provided excellent results for VCD simulations on similar systems previously. ${ }^{24-26}$ For some supplementary com- 

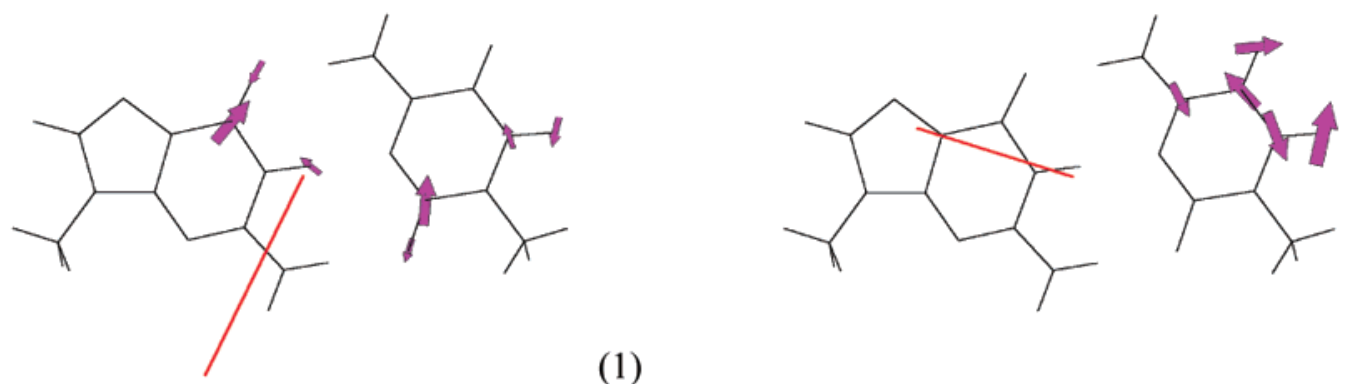

(1)

(2)
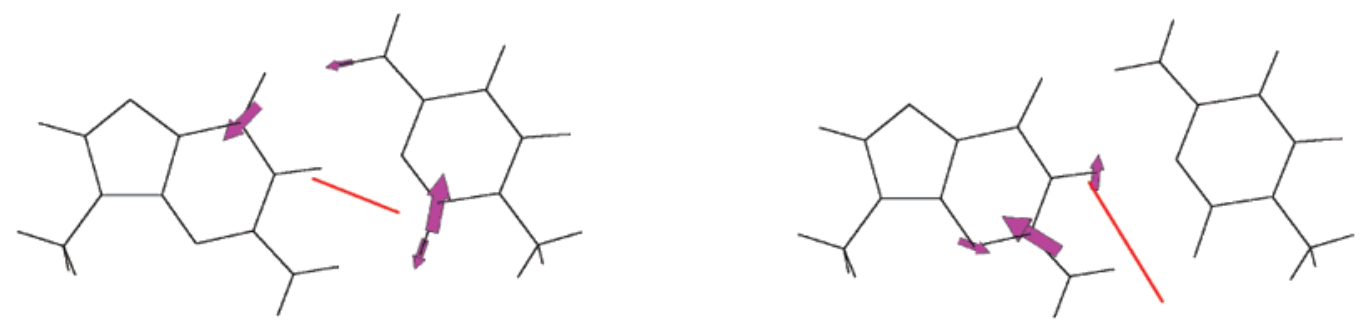

(3)

(4)
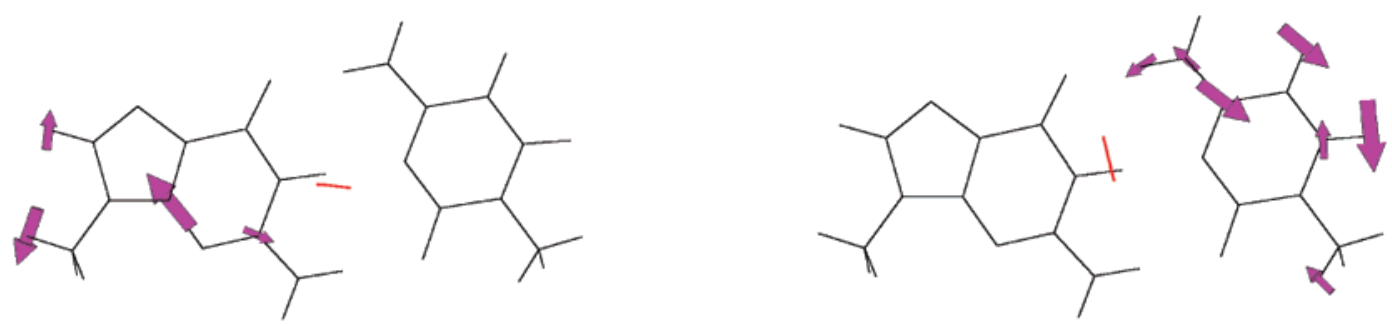

(5)

(6)
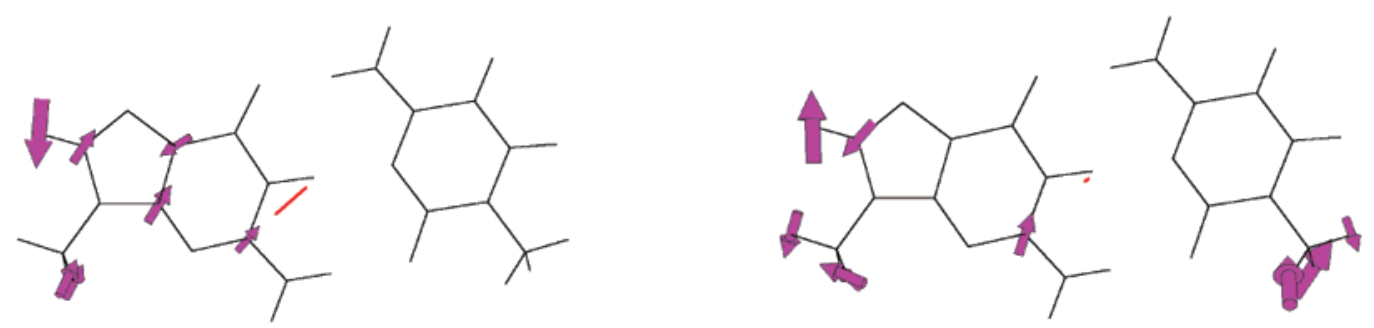

(7)

(8)

Figure 4. Characteristic CG base pair modes in the mid-IR region: calculated displacements (magenta arrows, size of the arrows is proportional to displacement magnitude) and size and direction of the transitional dipole moment (red lines). The mode numbers correspond to those in Table $1 b$ (experimentally in the range of $1500-1700 \mathrm{~cm}^{-1}$ ).

putations, $6-311++\mathrm{G}^{* *}$ and $6-31 \mathrm{G}$ basis sets were used as indicated below. The force field and intensity tensors were then transferred onto the octamer with the explicit water molecules. To mimic the experimental conditions, spectra of deuterated species (with all acidic hydrogens in the $\mathrm{N}-\mathrm{H}$ and $\mathrm{OH}$ groups replaced by deuteria) were simulated, which is a trivial task computationally. Absorption and VCD spectra were simulated using Lorentzian bands, $I(v) \sim\left[\delta^{2}+\left(v-v_{0}\right)^{2}\right]^{-1}$, with a default bandwidth of $\delta=10 \mathrm{~cm}^{-1}$ for smaller fragments (Figures 5, 8, 10) and $\delta=5 \mathrm{~cm}^{-1}$ for the oligonucleotides (Figures 11-13).

\section{Results and Discussion}

3.1. Experimental Spectra. The change of the VCD and absorption spectra under the $\mathrm{B}-\mathrm{Z}$ transition induced by the manganese ions can bee seen in Figure 3 . The spectra possess standard features of the B- and Z-form. ${ }^{11-16}$ Most of the DNA IR transitions have been assigned in previous studies. $6,16,32,38$ The transition is most pronounced in the region of $1600-1770$ $\mathrm{cm}^{-1}$, where the absorption maxima are shifted by up to 19 $\mathrm{cm}^{-1}$ and the FVCD couplet of the B-form (at 1691/1678 $\mathrm{cm}^{-1}$ ) changes sign (to \pm ) and its frequencies follow the absorption maxima to lower wavenumbers of $1671 / 1656 \mathrm{~cm}^{-1}$; changes in the rest of the bases $\left(1600-1350 \mathrm{~cm}^{-1}\right)$ and sugar-phosphate $\left(850-1000 \mathrm{~cm}^{-1}\right)$ vibration regions are less pronounced. More detailed assignments are given in the following sections. The VCD noise is estimated in the upper trace in Figure 3. The VCD signal, namely, in the sugar-phosphate region, is additionally obscured by a baseline drift. This can be partially improved by an optimization of the experiment for the lower-frequency part. ${ }^{12}$ Nevertheless, because of the low noise over all of the measured 


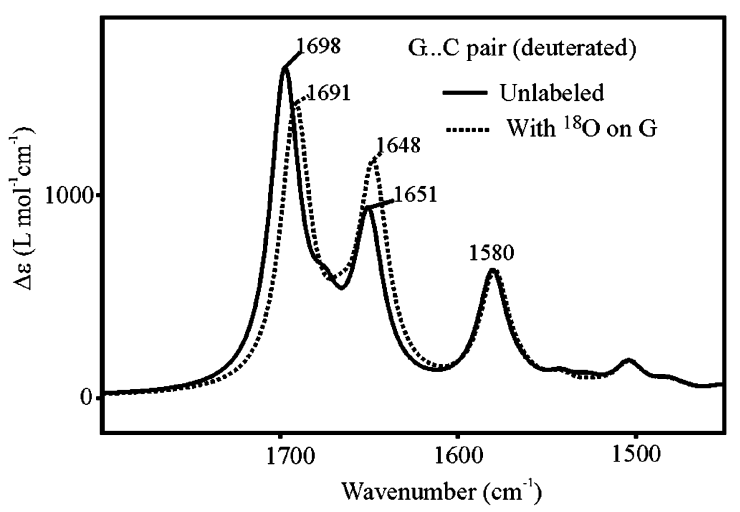

Figure 5. The effect of the guanine ${ }^{18} \mathrm{O}$ isotopic substitution on the absorption spectra of the G...C base pair. Full line, deuterated; dotted line, deuterated and ${ }^{18} \mathrm{O}$-labeled system. Although the cytosine remains unlabeled, its vibrational modes are also influenced via the coupling.

interval, we suppose that our spectra reflect the transition qualitatively correctly. The $\mathrm{D}_{2} \mathrm{O}$ absorption obscures the measurement at the $1150-1350 \mathrm{~cm}^{-1}$ region and is not captured in Figure 3. Because of the experimental experience, we neglect the contribution of the metal $\left(\mathrm{Mn}^{2+}\right)$ in the following simulation, as the IR and VCD spectral profiles are primarily given by the DNA molecule itself. This is consistent also with Raman DNA studies,${ }^{39,40}$ which monitor, namely, the structural dependence of the lower-frequency region $\left(600-700 \mathrm{~cm}^{-1}\right)$, usually unavailable to the VCD technique. Changes in the Raman spectra at the higher-frequency region upon the $\mathrm{B} \rightarrow \mathrm{Z}$ transition are more subtle and partially obscured by water absorption. However, the latest studies suggest that the vibrational Raman optical activity (ROA) may be more sensitive to DNA geometry also in the higher-frequency region (e.g., around $1680 \mathrm{~cm}^{-1}$ ). ${ }^{42}$

3.2. Building Blocks. Most DNA vibrational bands in the experimentally accessible region between 1800 and $800 \mathrm{~cm}^{-1}$ can be assigned to specific vibrational modes in the bases, sugar, and phosphate chromophores. Absorption and VCD responses of the "links" between these chromophores, typically the $\mathrm{C}-\mathrm{C}$ covalent bonds, are rather small. Identification of these link modes $(\mathrm{C}-\mathrm{C}-\mathrm{C}$ bending, $\mathrm{C}-\mathrm{H}$ bending, $\mathrm{C}-\mathrm{C}$ torsion, etc. $)$ is also prevented by their delocalization and mixing with other vibrational transitions.

Calculated wavenumbers for isolated bases (Figure 2) that contribute most to the DNA IR and VCD spectra are listed in Table 1a. Although they are generally close to expected experimental transitions, the $\mathrm{C}=\mathrm{O}$ stretching mode exhibits rather an unpleasant dependence on the size of the basis set. For Me-C, the smallest 6-31G basis provides quite a reasonable wavenumber of $1675 \mathrm{~cm}^{-1}$, but the medium-sized 6-31G** basis gives an extremely high value of $1743 \mathrm{~cm}^{-1}$, which again somewhat improves for the large $6-311++\mathrm{G}^{* *}$ basis set. Further computations (not shown here) confirmed that this is a rather general behavior of the $\mathrm{C}=\mathrm{O}$ bond observable for a wide range of quantum-chemical methods. Moreover, identification of this vibration is complicated also by the large frequency shift (50$70 \mathrm{~cm}^{-1}$, cf. Table 1a and 1b) upon formation of the external or internal hydrogen bond. This is in agreement with the properties of the $\mathrm{C}=\mathrm{O}$ stretching vibration in $N$-methylacetamide, found significantly dependent on the polarity of the solvent. ${ }^{43}$ Fortunately, this transition is strong in intensity and rather separated from others, and thus well distinguishable in the spectra.

Hydrogen bonding in the Watson-Crik G...C base pair elongates the $\mathrm{C}=\mathrm{O}$ bond (by $\sim 0.05 \AA$ if compared to the bare bases at the BPW91/6-311++ $\mathrm{G}^{* *}$ level) and causes a signifi-

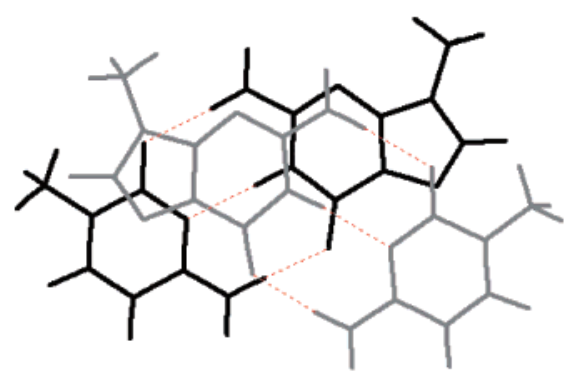

CG
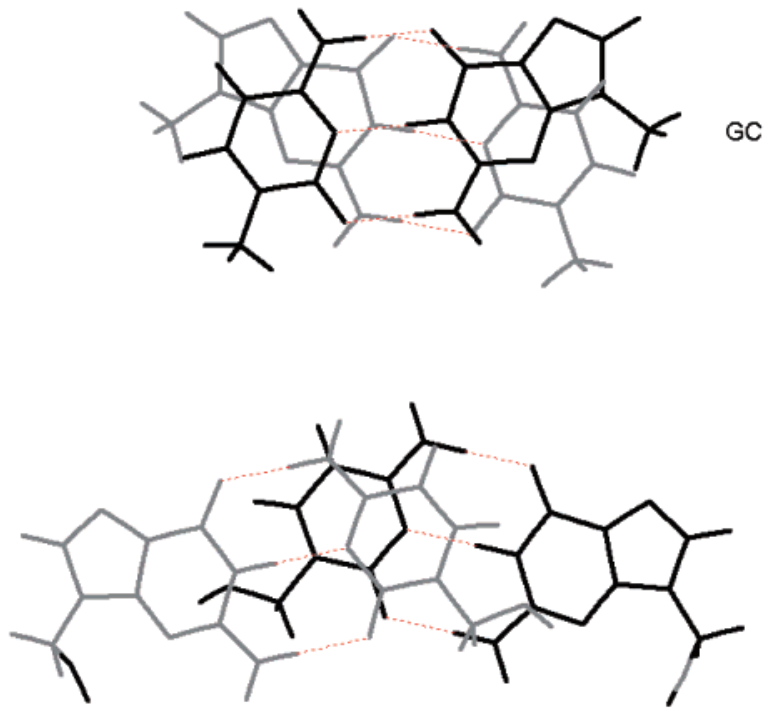

CG

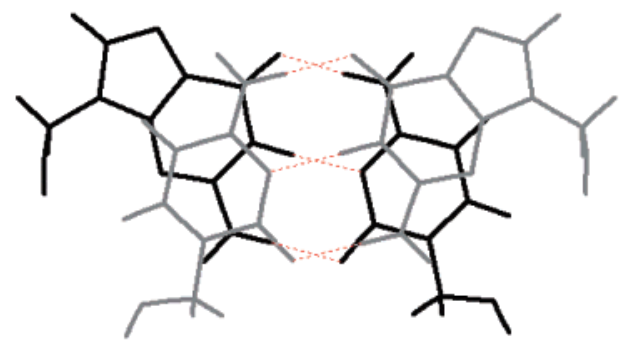

GC

Figure 6. Geometries of the stacked bases in the model $(\mathrm{C} . . . \mathrm{G})_{2}$ and $(\mathrm{G} . . . \mathrm{C})_{2}$ duplexes for the B- (top) and Z-(bottom) DNA forms. These differences in the stacking patterns are reflected in different absorption and VCD spectral patterns.

cant red shift of the $\mathrm{C}=\mathrm{O}$ stretching modes of about 30-90 $\mathrm{cm}^{-1}$ (cf. frequencies in Table $1 \mathrm{~b}$ ). An addition of five explicit water molecules to this base pair (third column in Table 1b) has a rather negligible influence on the frequencies of this modes. The water molecules were constrained approximately in the same plane as the base pair, so that they could be more easily propagated along the DNA molecule, but their distance to the base pair was optimized. The base-to-base interaction causes a strong coupling of the normal modes of the bases, as can be seen from the displacements in Figure 4. These modes are much more reminiscent of the modes in the DNA molecule than analogous vibrations in isolated cytosine and guanine. Nevertheless, some modes comprising atoms not involved in the hydrogen bonding (e.g., number 2 in Figure 4) are rather unchanged by the base pairing. As expected, for all the modes in this wavenumber region, the transitional dipole moment (red lines in Figure 4) lies approximately in the base pair plane.

Previously, the C...G interbase vibrational coupling was investigated experimentally by Howard and colleagues using 
TABLE 2: Calculated Hydrogen Bond Lengths $(\AA)$ in the Base Complexes

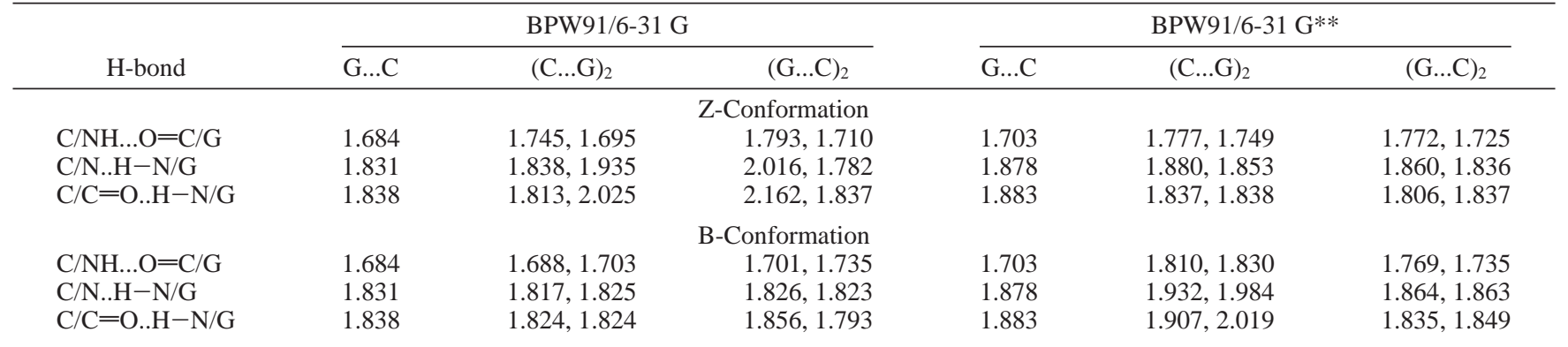

isotopically labeled guanine (by ${ }^{18} \mathrm{O}$ ) and used as additional evidence of a double-helix DNA formation. ${ }^{44}$ To reproduce these results, the oxygen in the guanine carbonyl group was replaced by ${ }^{18} \mathrm{O}$ and the absorption spectrum of the marked G...C pair was compared to the unlabeled (but still deuterated) pair in Figure 5. A very good agreement with the experiment can be observed: under the ${ }^{18} \mathrm{O}$ labeling the calculated (BPW91/6$31 \mathrm{G}^{* *}$ ) maxima at 1698 and $1651 \mathrm{~cm}^{-1}$ downshift by 7 and 3 $\mathrm{cm}^{-1}$, respectively. This corresponds to the experimental shifts observed in the interval of approximately $6-7 \mathrm{~cm}^{-1}$ for the higher-frequency and $1-6 \mathrm{~cm}^{-1}$ for the lower-frequency bands. ${ }^{44}$ The band at $1580 \mathrm{~cm}^{-1}$ is almost unaffected by the isotopic substitution, in accord with the experiment. As follows from the mode assignments in Table $1 \mathrm{~b}$ and Figure 4, the vibration of the guanine $\mathrm{C}=\mathrm{O}$ group is thus not only coupled to the carbonyl of the cytosine (modes 1 and 3) but also to the cytosine "breathing" (mode 2 ), although the relatively small $\mathrm{C}=$ $\mathrm{O}$ guanine movement is not visible in Figure 4 because of cutoffs used in the drawings for the atomic displacements. In a previous $\mathrm{HF} / 6-31 \mathrm{G}^{*}$ study of the C...G coupling, ${ }^{45}$ such analysis was obscured by the errors and systematic frequency shifts introduced by the neglect of the correlation energy. ${ }^{46}$ At the BPW91/ 6-31G** level, the ${ }^{18} \mathrm{O}$ isotopic effect could be reproduced also for hydrated C...G pairs and DNA helices.

There are two different stacking interactions for any regular conformation of the (dG-dC) $)_{n}$ oligomer corresponding to those in the $(\mathrm{GpC})_{2}$ and $(\mathrm{CpG})_{2}$ dinucleotides (Figure 6). Note also the substantial differences in the stacking patterns between the B- and Z-conformations. This stacking causes perturbations of the bases vibrations comparable to those caused by the hydrogen bonding. For example, in the $(\mathrm{C} . . \mathrm{G})_{2}$ dimer (Table 1c, first column), the $\mathrm{C}=\mathrm{O}$ stretching modes are split only by $9-12$ $\mathrm{cm}^{-1}$, while in (G...C) $)_{2}$ (Table 1d, first column), a giant split of $63 \mathrm{~cm}^{-1}$ for the $\mathrm{C}=\mathrm{O}$ stretching of cytosine is calculated and the ordering of the modes is changed because of the stacking interaction. The interaction of the base pairs in the dinucleotides was traditionally explained by the exciton dipolar coupling. ${ }^{32,47}$ However, the big frequency changes in Table 1c and the results of our detailed simulations (not included here) indicate that other interactions, such as dispersion or more complicated electrostatic perturbations, have to be considered to fully account for the splitting calculated ab initio. Also, as follows from the hydrogenbond lengths summarized in Table 2, the hydrogen bonding is perturbed by the duplex formations. Typically, the bonds become longer, in agreement with the slight frequency increase for the $\mathrm{C}=\mathrm{O}$ stretching modes.

Unlike the bases, the sugar-phosphate residues contribute mainly to the lower frequency region of the spectra and their vibrational modes are difficult to describe in terms of local coordinates. Their frequencies and assignments most contributing to IR and VCD spectra are listed in Table 1e. The complex character of these modes is demonstrated by the normal mode displacements in Figure 7. The displacements are dominated by the hydrogens but are primarily induced by torsional and bending changes in bonds connecting the heavy atoms.

3.3. The Role of Water. The vibrations described in the previous sections determine the basic character of the DNA IR spectra and even their basic VCD intensity pattern. However, interactions with the solvent contribute significantly to spectral intensities already for the individual molecular parts. This is documented in Figure 8 for absorption bands of the sugarphosphate fragment (top) and the base pair dimer (bottom). Clearly, the inclusion of the explicit water molecules causes a redistribution of spectral intensities and makes the simulated spectra more realistic with respect to the experimental data.

The absorption profile of the sugar-phosphate dimer in a vacuum is not reasonable, while the monomer with explicit water molecules provides a spectrum that compares better with the experiment. Thus, the calculated peak at $1205 \mathrm{~cm}^{-1}$ can be assigned to the experimental maximum around $1223 \mathrm{~cm}^{-1}$, although this asymmetric $\mathrm{P}=\mathrm{O}$ stretching vibration is obscured by the $\mathrm{D}_{2} \mathrm{O}$ signal in the experimental spectra of $\mathrm{D}_{2} \mathrm{O}$-based solutions. ${ }^{6,15,16}$ The frequency of the symmetric $\mathrm{P}=\mathrm{O}$ stretching mode calculated at 1022 in a vacuum shifts to $1062 \mathrm{~cm}^{-1}$ with
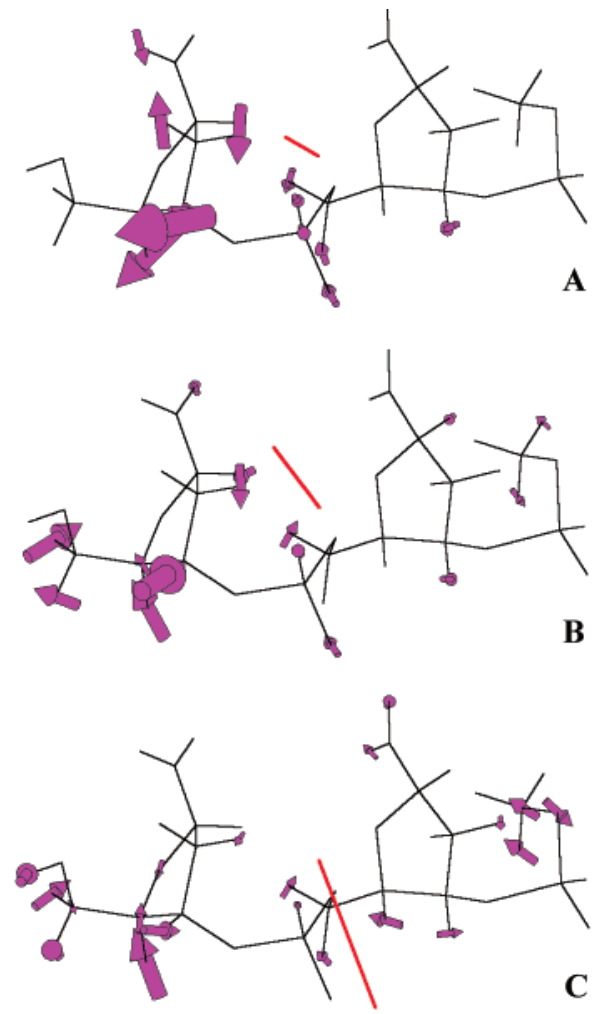

Figure 7. Examples of calculated normal modes in the sugarphosphate fragment: (A) out-of-phase $\mathrm{P}=\mathrm{O}$ stretching coupled with the $\mathrm{C}-\mathrm{H}$ bending modes (calculated at $1242 \mathrm{~cm}^{-1}$ ); (B) in-phase $\mathrm{P}=$ $\mathrm{O}$ stretching mode and sugar-ring deformation $\left(1080 \mathrm{~cm}^{-1}\right)$; and $(\mathrm{C})$ sugar ring $\mathrm{C}-\mathrm{O}$ stretching and deformation $\left(1022 \mathrm{~cm}^{-1}\right)$. 

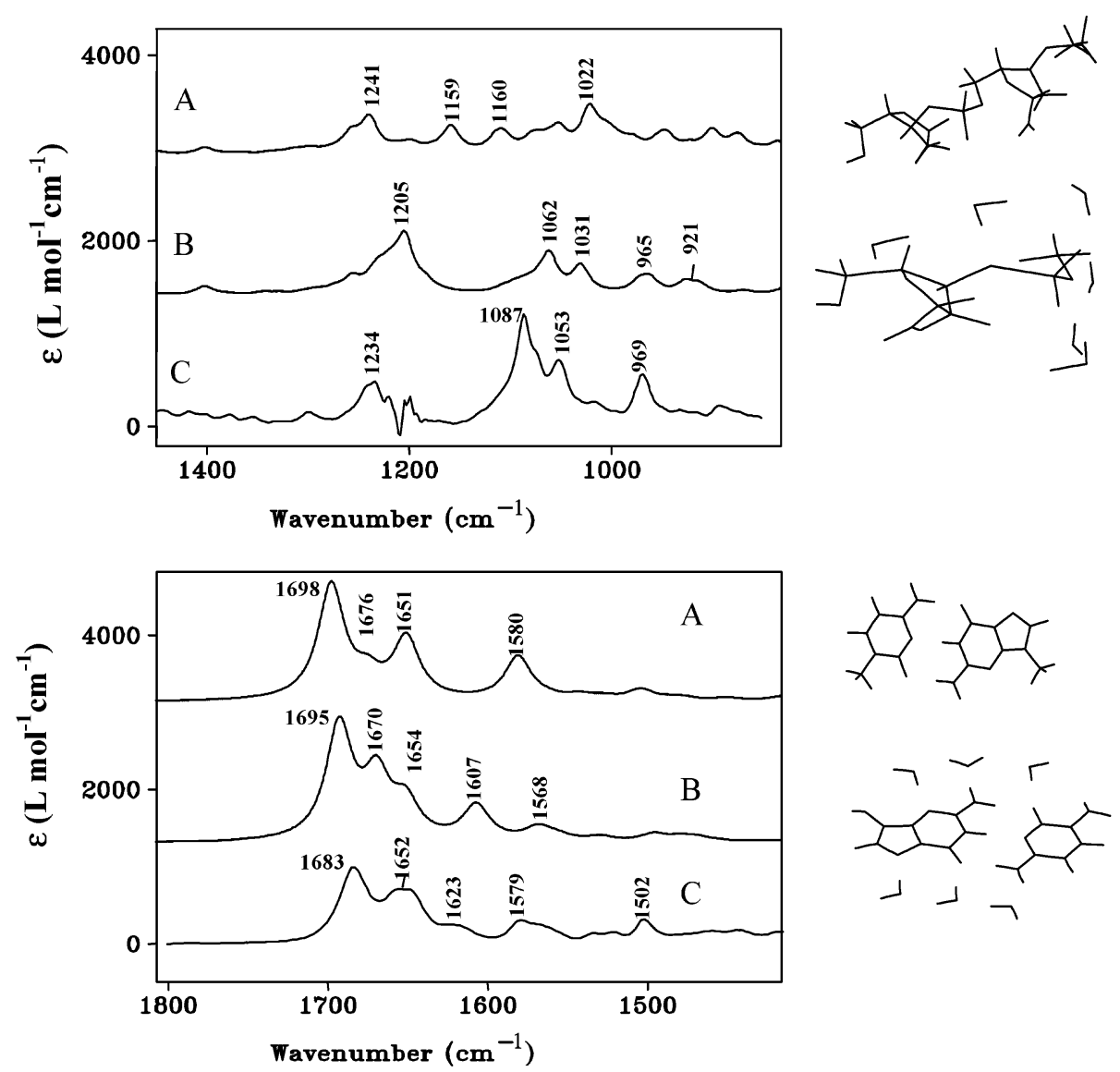

Figure 8. The influence of water on the absorption profile. (A) computation in a vacuum, (B) computation with explicit water molecules, (C) experiment; all computations were made at the BPW91/6-31G** level. At the top, spectra of a sugar-phosphate dimer in a vacuum and a hydrated sugar-phosphate segment are compared to the experimental spectra of B-DNA. A at the bottom, analogous comparison is made for the G...C duplex in a vacuum and surrounded by six water molecules.

$\mathrm{D}_{2} \mathrm{O}$ and its relative intensity becomes stronger so that it can be better related to the experimental peak at $1087 \mathrm{~cm}^{-1}$. This intensity increase may occur because of the increased strength of the dipole moment of the phosphate group because of phosphate interaction with water molecules. Similarly, the wavenumbers and intensities improve for the delocalized sugarphosphate modes at 1031 and $965 \mathrm{~cm}^{-1}$ in the hydrated system, which appear experimentally at 1053 and $969 \mathrm{~cm}^{-1}$, respectively.

The spectra of the bases (lower part of Figure 8) are less changed by the solvent, since some hydrogen bonds are formed already in the Watson-Crik base pair. The strongest absorption peak calculated at $1698 \mathrm{~cm}^{-1}$ moves to $1695 \mathrm{~cm}^{-1}$. Such a small change can be easily explained, since this signal appearing experimentally at $1683 \mathrm{~cm}^{-1}$ belongs to the stretching of the $\mathrm{C}=\mathrm{O}$ groups not exposed to the solvent. The smaller peaks at 1676 and $1651 \mathrm{~cm}^{-1}$ are more sensitive: the solvent reverses their relative intensities and the frequencies shift to 1670 and $1654 \mathrm{~cm}^{-1}$, respectively. The intensity increase for the peak at $1676 \mathrm{~cm}^{-1}$ (number 2 in Figure 4 and Table 1b) reflects the vulnerability of the cytosine $\mathrm{C}=\mathrm{O}$ group exposed to the solvent. We assign these transitions (calculated at 1670 and $1654 \mathrm{~cm}^{-1}$ ) to the broader band observed around $1652 \mathrm{~cm}^{-1}$, although its individual components are not well resolved. Finally, the vibrations involving the $-\mathrm{NH}_{2}$ groups appear to be most influenced by the solvent. The band at $1580 \mathrm{~cm}^{-1}$ splits into two, at $1607 \mathrm{~cm}^{-1}\left(\mathrm{C}-\mathrm{NH}_{2}\right.$ stretching of guanine) and 1568 $\mathrm{cm}^{-1}(\mathrm{C}=\mathrm{N}$ ring vibrations of guanine), which can be assigned to the experimental bands at 1623 and $1579 \mathrm{~cm}^{-1}$, respectively. The $1568 \mathrm{~cm}^{-1}$ vibration is very sensitive to the degree of

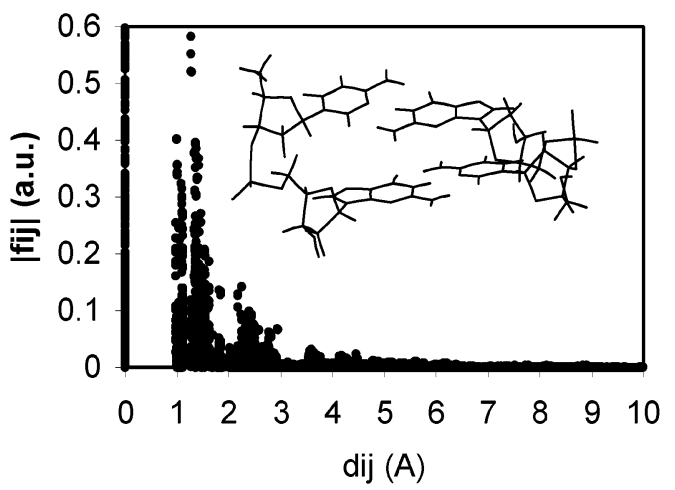

Figure 9. The dependence of the magnitude of the force constants $\left(f_{i \alpha, j \beta}=\partial^{2} E / \partial r_{i \alpha} \partial r_{i \beta}\right.$, for all Cartesian coordinates $\alpha, \beta$, all atoms $\left.i, j\right)$ on the atomic distances $\left(d_{i j}\right)$ as calculated at the PM3 level for the $(\mathrm{CpG})_{2}$ dinucleotide. For comparison, the $(\mathrm{CpG})_{2}$ molecule (approximately $20 \AA$ long) is inset in the graph.

hydration. Repeating the same calculation with five explicit water molecules instead of six led to a significantly reduced intensity of this absorption.

3.4. The Origin of the VCD Signal. As was pointed out previously, VCD is a short-range phenomenon. ${ }^{10}$ The strongest signal is usually mediated by covalent $\sigma$-bonds or by interactions of groups close in space. For the base pair, we attempted to quantify the distance over which the atoms "feel each other" in Figure 9, where the dependence of the force constants (properties of two atoms) on the interatomic distances is plotted. Apparently, the interactions quickly vanish for atoms separated by more than 4-5 . Taking into account that the distance between pairs of 

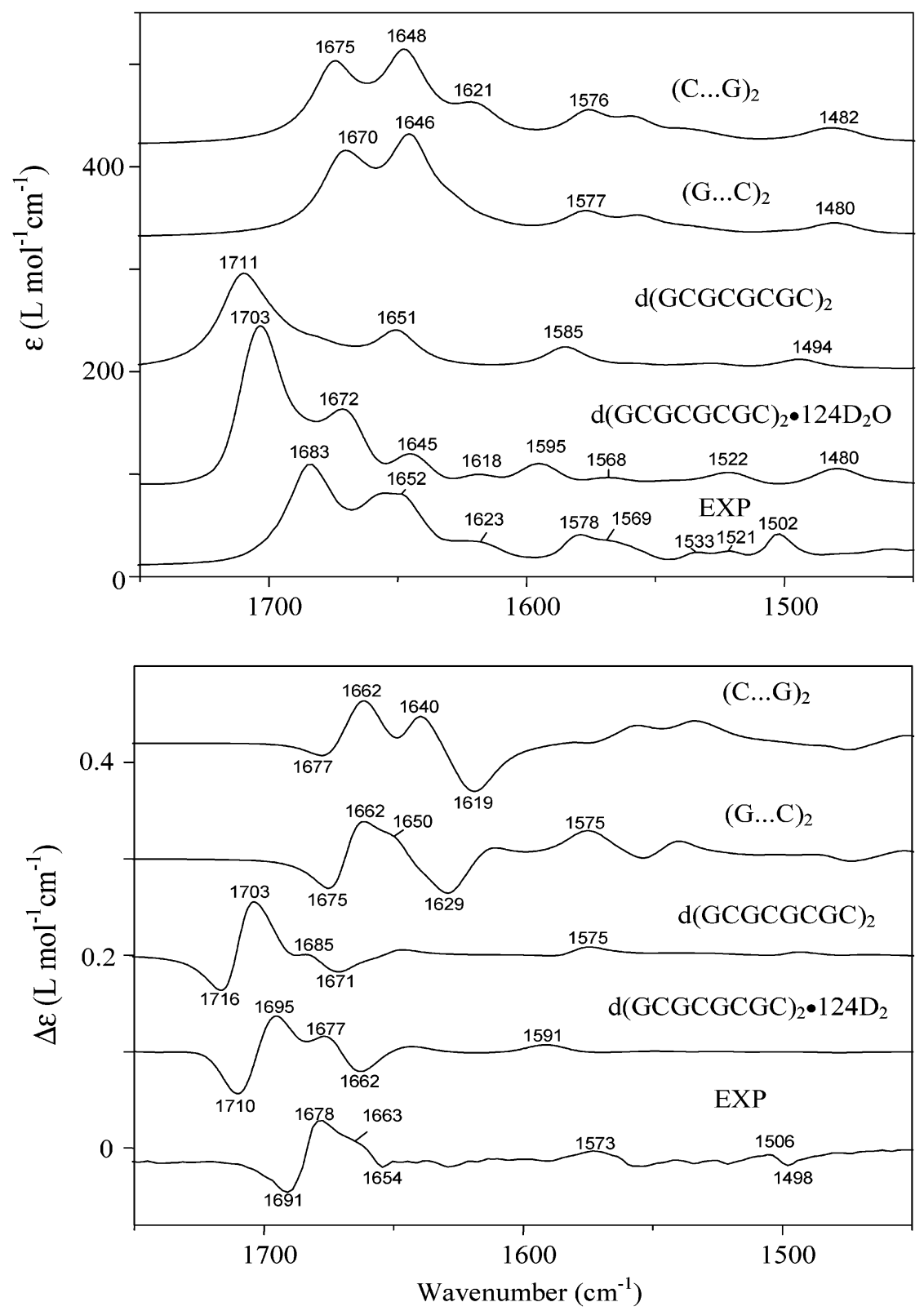

Figure 10. Absorption $(\epsilon)$ and $\operatorname{VCD}(\Delta \epsilon)$ spectra of the B-conformation in the $1750-1450 \mathrm{~cm}^{-1}$ region. Comparison of the simulations for the $(\mathrm{C} \ldots \mathrm{G})_{2}$ and $(\mathrm{G} . . \mathrm{C})_{2}$ fragments (calculated directly at BPW/6-31G), for the d(GCGCGCGC) $)_{2}$ and d(GCGCGCGC) ${ }_{2} \cdot 124 \mathrm{D}_{2} \mathrm{O}$ octanucleotides $(\mathrm{BPW} 91 /$ 6-31G** by the tensor transfer), and the experimental spectra.

bases in DNA is about $3.5 \AA$, we consider sufficient to calculate the force constants for the $(\mathrm{G} . . . \mathrm{C})_{2}$ and $(\mathrm{C} . . \mathrm{G})_{2}$ fragments (Figure 5)-this restriction was also dictated by the limitations of our computer resources. On the other hand, a further neglecting of the closer-range interaction would have lead to unreasonable spectra.

Indeed, the short-range approximation provides realistic absorption and VCD spectra in the region dominated by the vibration of the bases (Figure 10). Thus, the spectrum of the octamer d(GCGCGCGC) $)_{2}$ can be roughly thought of as a sum of the $(\mathrm{GpC})_{2}$ and $(\mathrm{CpG})_{2}$ dimers, but the intensities are also somewhat influenced by a longer range normal mode coupling. The absorption and VCD bands for d(GCGCGCGC $)_{2}$ are shifted toward higher energies compared to the $(\mathrm{G} . . . \mathrm{C})_{2}$ and $(\mathrm{C} \ldots \mathrm{G})_{2}$ fragments calculated with the 6-31G basis set. This shift is introduced by the error of $6-31 G^{* *}$ basis set. This basis set was used for computations of G...C base pair and the resulting parameters were overlapped to the octamer at the very end, thus overwriting some of the parameters derived from the dimer computations (see Table 1). The VCD intensity in this region arises mainly from the $\mathrm{C}=\mathrm{O}$ stretching vibrations with large transition dipole moments.

The strongest VCD signal is a $\mp$ couplet caused by the interaction of the $\mathrm{C}=\mathrm{O}$ groups located on guanine residues with calculated peaks at $1716(-) / 1703(+) \mathrm{cm}^{-1}$ and corresponding to an absorbance maximum at $1711 \mathrm{~cm}^{-1}$. The VCD frequencies are lowered to $1710(-) / 1695(+) \mathrm{cm}^{-1}$ by the inclusion of explicit water molecules for the hydrated system $\mathrm{d}(\mathrm{GCGCGCGC})_{2} \cdot 124 \mathrm{H}_{2} \mathrm{O}$. The absorption band is also shifted down to $1703 \mathrm{~cm}^{-1}$. Both VCD and absorption bands can be convincingly assigned to the experimental signal at $1691(-) /$ $1678(+) \mathrm{cm}^{-1}$ with the corresponding absorption at $1683 \mathrm{~cm}^{-1}$.

For the d(GCGCGCGC) $)_{2}$ molecule, another couplet at 1685$(+) / 1671(-) \mathrm{cm}^{-1}$ was calculated as a positive shoulder with lower relative intensity and a negative VCD band in Figure 10, corresponding mostly to the stretching of the $\mathrm{C}=\mathrm{O}$ groups on the cytosine residues. For the d(GCGCGCGC $)_{2} \cdot 124 \mathrm{H}_{2} \mathrm{O}$ hydrated system, this couplet is again shifted to the lower 


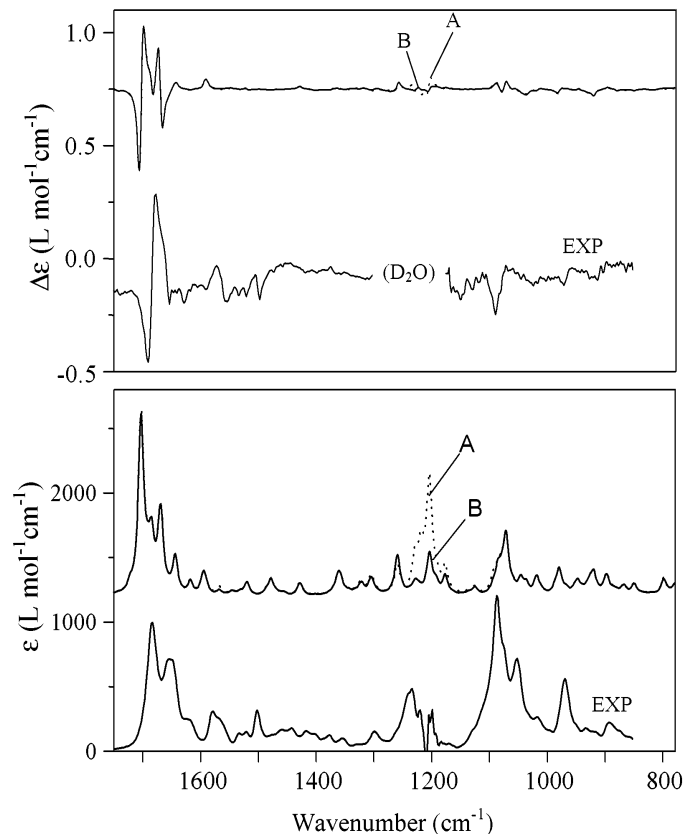

Figure 11. Contribution of the water envelope to the VCD $(\Delta \epsilon)$ and absorption $(\epsilon)$ spectra for the B-conformation. (A) full simulation for $\mathrm{d}(\mathrm{GCGCGCGC})_{2} \cdot 124 \mathrm{D}_{2} \mathrm{O}$; (B) simulation without the signal from the water molecules. For B, the atomic polar and axial intensity tensors for the water atoms were set to zero, but the full vibrational coupling remained (unlike in Figure 8). The region of the $\mathrm{D}_{2} \mathrm{O}$ absorption was left out in the experimental VCD spectrum.

wavenumbers of $1677(+) / 1662(-) \mathrm{cm}^{-1}$ and is more pronounced, with a clear positive peak instead of a shoulder. This couplet can be clearly related to the experimental signal at 1663$(+) / 1654(-) \mathrm{cm}^{-1}$. However, the positive counterpart of the experimental peak at $1663 \mathrm{~cm}^{-1}$ appears as a shoulder rather than a distinct peak because of overlap with the signal from the guanine vibration. In this aspect, the observed spectrum appears to approach a "middle way" between the vacuum and solvent model, which may correspond to an incomplete hydration of the base pair because of steric and time-dependent effects in real systems.

3.5. Contribution of the Water Envelope to Spectral Intensities. Computationally, it is possible to see contributions of individual atoms to the spectral intensities. Since the attachment of the water to DNA in the first hydration sphere is relatively strong and it influences many DNA modes, one may ask what is its contribution to the spectra. As apparent from Figure 11, it has a rather negligible signal except for the experimentally unusable $\mathrm{D}_{2} \mathrm{O}$ deformation region around 1200 $\mathrm{cm}^{-1}$. In Figure 10, only the intensity contribution of the water atoms is separated out while the mechanical (force field) coupling is still present, unlike in section 3.3. The strong absorption band appearing in the calculated spectrum of the hydrated system around $1230 \mathrm{~cm}^{-1}$ (trace A in Figure 11), which constitutes the main difference between the two traces, arises from the $\mathrm{D}_{2} \mathrm{O}$ deformation mode and is overlapped with the phosphate asymmetric vibration at $1223 \mathrm{~cm}^{-1}$. The phosphate band still contributes to the calculated absorption spectrum if the water signal is subtracted (trace B in Figure 11). Such a minor intensity originating in the solvent partially justifies vacuum-based and continuous-solvent model simulations and suggests that the solvent influences practically only vibrations of the boundary atoms. This is in agreement with the short range of the interatomic forces displayed in Figure 9. Unlike for natural $\mathrm{H}_{2} \mathrm{O}$, the deformation vibration of $\mathrm{D}_{2} \mathrm{O}$ lies near the absorption

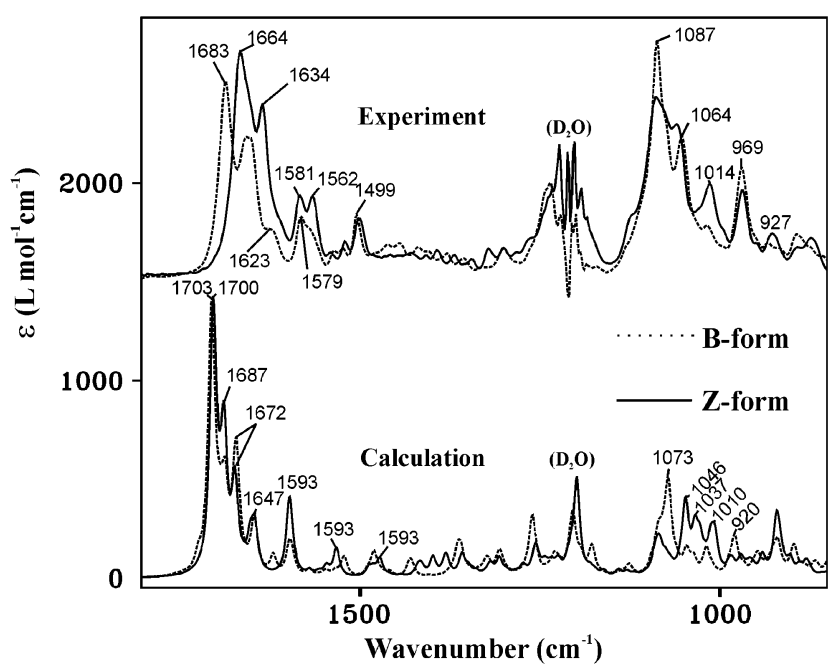

Figure 12. Experimental $\left((\mathrm{dG}-\mathrm{dC})_{20}\right)$ and calculated (d(GCGCGCGC) $)_{2}$. $124 \mathrm{D}_{2} \mathrm{O}$, at the BPW91/6-31G** level for the fragments) absorption spectra for the B- and Z- forms of DNA.

of the asymmetric $\mathrm{P}=\mathrm{O}$ stretching and other sugar-phosphate modes and thus can indirectly influence the spectra. This may explain some variations in experimental results dealing with this region. Direct effect of a chirally arranged solvent along the DNA helix is small (upper part of Figure 11) and cannot be observed because of the limited sensitivity of current VCD spectrometers.

3.6. The $B \rightarrow Z$ Transition of $d(\text { GCGCGCGC })_{2}$. The $B-Z$ transition causes relatively modest changes in the absorption spectra. Nevertheless, several of them can be simulated with our modeling as shown in Figure 12. Peak frequencies and assignments are also briefly summarized in Table 3. Upon the $\mathrm{B} \rightarrow \mathrm{Z}$ transition, the experimentally observable peak at 1683 $\mathrm{cm}^{-1}$ moves to $1664 \mathrm{~cm}^{-1}$. This red shift is only partially explained by the model $\left(1703\right.$ to $\left.1700 \mathrm{~cm}^{-1}\right)$. The intensity of the experimental band at $1579 \mathrm{~cm}^{-1}$ increases and the shoulder at $1562 \mathrm{~cm}^{-1}$ evolves into a peak. In the modeled spectra, only a single band at $1593 \mathrm{~cm}^{-1}$ is present in this region, but its intensity clearly rises following the transition. In the wavenumber region of the sugar-phosphate residue, the experimental band at $1087 \mathrm{~cm}^{-1}$ loses intensity, which is reflected by the calculation as a reduction of the band at $1073 \mathrm{~cm}^{-1}$. The increased intensity of the 1064 and $1014 \mathrm{~cm}^{-1}$ peaks in the $\mathrm{Z}$-form is nicely reproduced by the computed intensity of the 1046 and $1037 \mathrm{~cm}^{-1}$ absorptions.

The transition is more obvious in the VCD spectra in Figure 13. Since the transition is less pronounced for the sugarphosphate vibrations ${ }^{48}$ and our experiment was not optimized for the lower-frequency region, we discuss only the differences in the region of bases vibrations $\left(\sim 1400-1750 \mathrm{~cm}^{-1}\right)$. The experimental VCD spectrum (upper part of Figure 13) of the $\mathrm{B}$-form is dominated by the $\mp$ couplet at $1691 / 1678 \mathrm{~cm}^{-1}$ of the $\mathrm{C}=\mathrm{O}$ stretch of guanine. The signs and wavenumber splitting are well-reproduced by the computation $(1710(-) / 1695(+)$ $\left.\mathrm{cm}^{-1}\right)$. This couplet reverses its sign in the Z-form, yielding a positive peak at 1671 and a negative peak at $1656 \mathrm{~cm}^{-1}$. This change is faithfully reproduced by the simulation, although the wavenumber shift is somewhat smaller giving corresponding theoretical peaks at $1707(+) / 1693(-) \mathrm{cm}^{-1}$.

As pointed out above, the $\mathrm{C}=\mathrm{O}$ groups of cytosine contribute mainly to the second couplet in the experimental spectra of the B-form. Its $( \pm)$ sign is reproduced by the computation although the computed wavenumbers at $1677(+) / 1662(-) \mathrm{cm}^{-1}$ are more 
TABLE 3: Experimental (for $(\mathrm{dG}-\mathrm{dC})_{20}$ ) and Calculated (for d(GCGCGCGC) $\boldsymbol{}_{\mathbf{2}} \mathbf{1 2 4}_{\mathbf{2}} \mathrm{O}$ ) Absorption and VCD Bands $\left(\mathrm{cm}^{-1}\right)$ for B- and Z-Forms

\begin{tabular}{|c|c|c|c|c|c|c|c|c|}
\hline \multicolumn{4}{|c|}{ B-form } & \multicolumn{4}{|c|}{ Z-form } & \multirow[b]{3}{*}{ assignment } \\
\hline \multicolumn{2}{|c|}{ experimental } & \multicolumn{2}{|r|}{ calculated } & \multicolumn{2}{|r|}{ experimental } & \multicolumn{2}{|r|}{ calculated } & \\
\hline abs & VCD & abs & VCD & abs & VCD & abs & VCD & \\
\hline 1683 & $1691(-) / 1678(+)$ & 1703 & $1710(-) / 1695(+)$ & 1664 & $1671(+) / 1656(-)$ & 1700 & $1707(+) / 1693(-)$ & $\nu^{a}(\mathrm{C}=\mathrm{O}) / \mathrm{G}$ \\
\hline \multirow{2}{*}{$1657-1649$} & $1663(+) / 1654(-)$ & 1672 & $1677(+) / 1662(-)$ & 1634 & $1637(-) / 1627(+)$ & 1672 & $1680(+) / 1665(-)$ & $v(\mathrm{C}=\mathrm{O}) / \mathrm{C}$ \\
\hline & $1637(+)$ & 1645 & $1643(+)$ & & & 1647 & $1657(+) / 1649(-)$ & $v(\mathrm{C}=\mathrm{C}) / \mathrm{C}+v(\mathrm{C}=\mathrm{O}) / \mathrm{G}$ \\
\hline 1623 & $1627(-)$ & 1618 & $1618(-)$ & & & & & \\
\hline 1579 & $1573(+)$ & 1593 & $1591(+)$ & 1581 & & 1593 & $1603(-)$ & $v\left(\mathrm{C}-\mathrm{NH}_{2}\right) / \mathrm{G}$ \\
\hline 1564 & $1570(+) / 1556(-)$ & 1568 & & 1563 & $1561(-)$ & & & $v(\mathrm{C}=\mathrm{N}) / \mathrm{G}$ \\
\hline 1534 & $1540(+) / 1535(-)$ & & & & & & & \\
\hline 1521 & $1527(+) / 1521(-)$ & 1522 & & 1521 & & 1532 & & $\delta\left(\mathrm{C}-\mathrm{NH}_{2}\right)+\operatorname{def} / \mathrm{C}$ \\
\hline 1502 & $1506(+) / 1498(-)$ & 1479 & & 1499 & $1502(-) / 1492(+)$ & 1473 & & $v(\mathrm{C}=\mathrm{N}) / \mathrm{C}$ \\
\hline 1087 & 1089(-)/1070(+) & 1073 & & 1087 & $1087(+)$ & 1084 & $1087(-)$ & symm. $v(\mathrm{P}=\mathrm{O})+v\left(\mathrm{C}^{\prime}-\mathrm{O} 5^{\prime}\right)$ \\
\hline 1053 & & 1044 & & 1060 & & 1046 & & $v(\mathrm{C}-\mathrm{O}) /$ deoxyribose \\
\hline 1018 & & 1018 & & 1014 & & 1010 & & phosphodiester \\
\hline \multirow[t]{2}{*}{969} & $973(-) / 958(+)$ & 980 & & 969 & $969(+)$ & 968 & & backbone coupled to \\
\hline & & 922 & & 927 & & 920 & & sugar motions and \\
\hline 892 & & 897 & & 873 & & 897 & & glycosidic bond torsion \\
\hline
\end{tabular}

${ }^{a} \nu$, stretching; $\delta$, bending.

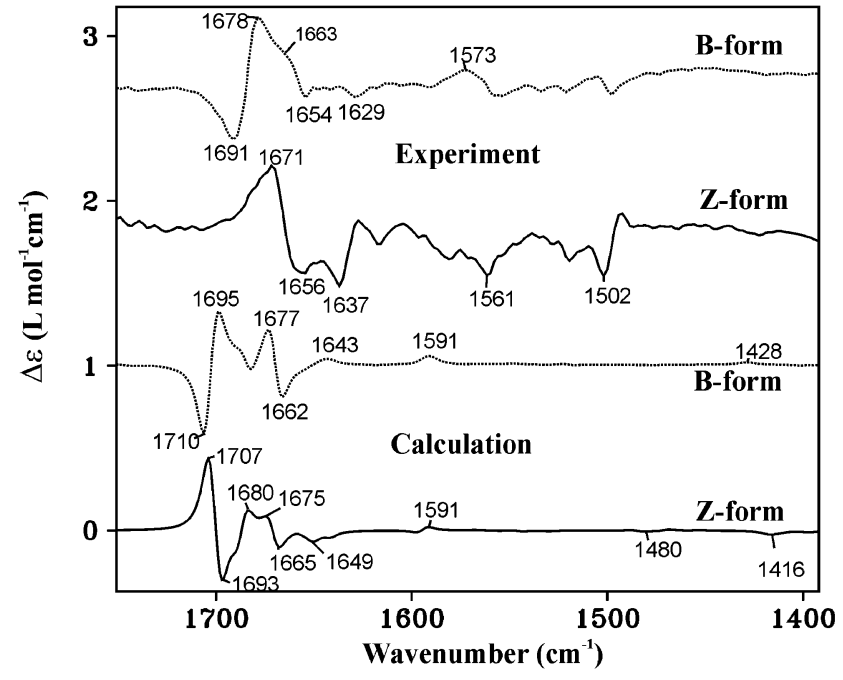

Figure 13. Experimental ((dG-dC) $\left.)_{20}\right)$ and calculated (d(GCGCGCGC) ${ }_{2} \cdot$ $124 \mathrm{D}_{2} \mathrm{O}$, at BPW91/6-31G**) VCD spectra for the B- and Z- DNA forms in the higher-frequency region.

separated from the guanine couplet than the experimental ones at $1663(+) / 1654(-) \mathrm{cm}^{-1}$. The $( \pm)$ conservative pattern for this vibration is lost in the experimental spectra for the Z-conformation, probably being overlapped with the $\mathrm{C}=\mathrm{O}$ stretching signal from guanine, and is visible as one negative band at $1637 \mathrm{~cm}^{-1}$. Theoretically, a larger splitting between the guanine and cytosine $\mathrm{C}=\mathrm{O}$ stretching modes is predicted, so that the guanine signal can be distinguished in peaks at $1680(+), 1675(+)$, and 1665$(-) \mathrm{cm}^{-1}$.

The contribution of other vibrational modes of the bases (below $1600 \mathrm{~cm}^{-1}$, see Tables $1 \mathrm{~b}$ and 3 ) to the VCD spectra is obscured by an unfavorable signal-to-noise ratio in this region. For the B-form, the positive signal experimentally observed at $1573 \mathrm{~cm}^{-1}$ corresponds to the calculated positive peak at 1591 $\mathrm{cm}^{-1}$ and thus can be assigned to the $\mathrm{C}-\mathrm{NH}_{2}$ stretching mode of guanine (mode number 4 in Figure 4). Its absence in the experimental spectra of the Z-form can be explained by the loss of intensity and its transmutation into a couplet predicted by the computation. Supposedly, more detailed analysis of this and also the sugar-phosphate region can be done in the future when the accuracies of both experimental and theoretical methods are improved.

\section{Conclusions}

We have developed and successfully tested the method of generating IR and VCD spectra for the DNA oligonucleotides. The method is based on ab initio computations of molecular fragments, requires minimum ad hoc parameters (currently mainly the geometry of the modeled molecules), and can be systematically improved in the future. Most characteristic changes in the absorption and VCD frequencies and intensities observed for the $\mathrm{B}-\mathrm{Z}$ transition could be interpreted with the simulations. Spectral intensities of DNA are significantly modulated by specific hydrogen-bond interactions with water, which can be included in the modeling via explicit water molecules. Mode assignments to individual DNA parts are in general agreement with previous studies, providing that the base pairs are considered as autonomous chromophores. The modeling reflects correctly main intensity features in the bases vibration region, unlike the older oscillator models. Weaker intensity transitions in the lower-frequency region could not be explained, partially because of the experimental noise. The combination of the VCD spectroscopy with molecular modeling appears essential for VCD studies of DNA structure.

Acknowledgment. The work was supported by grants of the Grant Agency of the Czech Republic (203/01/0031) and Grant Agency of the Academy of Sciences (A4055104) to P.B., by a grant from Natural Sciences and Engineering Research Council of Canada (NSERC) to H.W., and by a grant from the Alberta Heritage Foundation for Medical Research (AHFMR) to V.A.

\section{References and Notes}

(1) Pohl, F. M.; Jovin, T. M. J. Mol. Biol. 1972, 67, 375.

(2) Pohl, F. M. Nature 1976, 260, 365.

(3) van de Sande, J. H.; McIntosh, L. P.; Jovin, T. M. EMBO J. 1982, 1,777 .

(4) Rossetto, F. E.; Nieboer, E. J. Inorg. Biochem. 1994, 54, 167.

(5) Saenger, W. Principles of nucleic acid structure; Springer-Verlag: New York, 1984.

(6) Taillandier, E.; Liquier, J.; Taboury, J. A. In Advances in Infrared and Raman Spectroscopy; Clark, R. J. H., Hester, R. E., Eds.; Wiley Heyden: New York, 1985; Vol. 12, pp 65-114.

(7) Nordheim, A.; Rich, A. Nature 1983, 303, 674

(8) Melcher, T.; Maas, S.; Herb, A.; Sprengel, R.; Seeburg, P. H.; Higuchi, M. Nature 1996, 379, 460.

(9) Berger, I.; Winston, W.; Manoharan, R.; Schwartz, T.; Alfken, J.; Kim, Y. G.; Lowenhaupt, K.; Herbert, A.; Rich, A. Biochemistry 1998, 37 , 13313. 
(10) Keiderling, T. A. In Circular dichroism and the conformational analysis of biomolecules; Fasman, G. D., Ed.; Plenum Press: New York, 1996; pp 555-597.

(11) Gulotta, M.; Goss, D. J.; Diem, M. Biopolymers 1989, 28, 2047.

(12) Wang, L.; Yang, L.; Keiderling, T. A. Biophys. J. 1994, 67, 2460.

(13) Andrushchenko, V. V.; van de Sande, J. H.; Wieser, H.; Kornilova,

S. V.; Blagoi, Yu. P. J. Biomol. Struct. Dyn. 1999, 17, 545

(14) Birke S. S.; Diem, M. Biophys. J. 1995, 68, 1045.

(15) Tsuboi, M. Appl. Spectrosc. Rev. 1969, 3, 45.

(16) Tsuboi, M. In Basic Principles in Nucleic Acid Chemistry; Ts'o, P.

O. P., Ed.; Academic Press: New York, 1974; pp 400-451.

(17) Stephens, P. J. J. Phys. Chem. 1985, 89, 748.

(18) Xiang, T.; Goss G. J.; Diem, M. Biophys. J. 1993, 65, 1255.

(19) Zhong, W.; Gulotta, M.; Goss, D. J.; Diem, M. Biochemistry 1990, 29,7485 .

(20) Maharaj, V.; Rauk, A.; van de Sande, J. H.; Wieser, H. J. Mol. Struct. 1997, 408, 315.

(21) Rauk, A.; Yang, D. J. Phys. Chem. 1992, 96, 437.

(22) Charney, E. The Molecular basis of Optical Activity; John Wiley \& Sons: New York, 1979.

(23) Bouř, P.; Keiderling, T. A. J. Am. Chem. Soc. 1992, 114, 9100.

(24) Bouř, P.; Keiderling, T. A. J. A. Chem. Soc. 1993, 15, 9602.

(25) Bouř, P.; Kubelka, J.; Keiderling, T. A. Biopolymers 2000, 53, 380.

(26) Silva, R. A. G. D.; Kubelka, J.; Boür, P.; Decatur, S. M.; Keiderling,

T. A. Proc. Natl. Acad. Sci. U.S.A. 2000, 97, 8318.

(27) Cheeseman, J. R.; Frisch, M. J.; Devlin F. J.; Stephens, P. J. Chem.

Phys. Lett. 1996, 252, 211.

(28) Bouř, P.; Sopková, J.; Bednárová, L.; Maloň, P.; Keiderling, T. A. J. Comput. Chem. 1997, 18, 646.

(29) Tsankov, D.; Eggimann, T.; Wieser, H. Appl. Spectrosc. Rev. 1995 $49,132$.

(30) Scuseria, G. E. J. Phys. Chem. A 1999, 103, 4782.

(31) Kubelka, J. Ph.D. Thesis, University of Illinois at Chicago, 2002.

(32) Maharaj, V. Ph.D. Thesis, University of Calgary, 1996.

(33) Insight II.; Biosym/MSI/Accelrys Inc.: San Diego, CA, 1995.
(34) Zhanpeisov, N. U.; Leszczynski, J. J. Phys. Chem. A 1998, 102, 6167.

(35) Frisch M. J.; Trucks, G. W.; Schlegel, H. B.; Scuseria, G. E.; Robb, M. A.; Cheeseman, J. R.; Zakrzewski, V. G.; Montgomery, J. A.; Stratmann, R. E.; Burant J. C.; Dapprich, S.; Millam, J. M.; Daniels, A. D.; Kudin, K. N.; Strain, M. C.; Farkas, O.; Tomasi, J.; Barone, V.; Cossi, M.; Cammi, R.; Mennucci, B.; Pomelli, C.; Adamo, C.; Clifford, S.; Ochterski, J.; Petersson, G. A.; Ayala, P. Y.; Cui, Q.; Morokuma, K.; Malick, D. K.; Rabuck, A. D.; Raghavachari, K.; Foresman, J. B.; Cioslowski, J.; Ortiz, J. V.; Stefanov, B. B.; Liu, G.; Liashenko, A.; Piskorz, P.; Komaroni, I.; Gomperts, R.; Martin, R. L.; Fox, D. J.; Keith, T.; Al-Laham, M. A.; Peng, C. Y.; Nanayakkara, A.; Gonzales, C.; Challacombe, M.; Gill, P. M. W.; Johnson, B. G.; Chen, W.; Wong, M. W.; Andres, J. L.; Head-Gordon, M.; Replogle, E. S.; Pople, J. A. Gaussian 98, revisions A.7 and A.9; Gaussian, Inc.: Pittsburgh, PA, 1998.

(36) Becke, A. D. J. Chem. Phys. 1993, 98, 5648.

(37) Perdew, J. P.; Wang, Y. Phys. Rev. B 1992, 45, 13244.

(38) Taillandier, E.; Liquier, J. In Methods in Enzymology; Lilley, D., Dahlberg, J., Eds.; Academic Press Inc.: San Diego, CA, 1992; pp 307335 .

(39) Žaludová, R.; Natile, G.; Brabec, V. Anti-Cancer Drug Des. 1997, $12,295$.

(40) Peticolas, W. L.; Thomas, G. A. J. Mol. Struct. 1985, 126, 509.

(41) Thomas, G. J., Jr.; Tsuboi, M. Adv. Biophys. Chem. 1993, 3, 1.

(42) Bell, A. F.; Hecht, L.; Barron, L. D. J. Raman Spectrosc. 1999, 30,651 .

(43) Kubelka, J.; Keiderling, T. A. J. Phys. Chem. A 2001, 105, 10922.

(44) Howard, F. B.; Frazier, J.; Miles, H. T. Proc. Natl. Acad. Sci. U.S.A. 1969, 64, 451 .

(45) Florián, J.; Leszczynski, J. Int. J. Quantum Chem.: Quantum Biol. Symp. 1995, 22, 207.

(46) Florián, J.; Baumruk, V.; Leszczynski, J. J. Phys. Chem. 1996, 100, 5578 .

(47) Tinoco, I. Radiat. Res. 1963, 20, 133.

(48) Wang, L. Ph.D. Thesis, University of Illinois at Chicago, 1993. 